\title{
Novelty of continuous intravenous infusion of bumetanide in severe congestive heart failure associated with renal failure
}

\author{
Anil K Mandal* \\ *Consultant Nephrologist, Putnam Community Medical Center, Palatka, Florida, USA \\ ${ }^{*}$ Clinical Professor of Medicine, University of Florida at Gainesville, Florida, USA
}

\begin{abstract}
This study describes efficacy of continuous infusion of bumetanide in severe congestive heart failure (CHF) associated with severe renal failure. Renal failure progresses as $\mathrm{CHF}$ advances. Renin-angiotensin inhibitor drugs consisting of angiotensin converting enzyme inhibitor and angiotensin receptor blocker are main stay of therapy in CHF. These drugs aggravate renal failure, decrease urine output, make patients fluid overloaded and more short of breath, warranting repeated hospitalization for relief of shortness of breath. Diuretic therapy in the form of bolus help but continuous infusion of diuretic therapy in the form of furosemide or bumetanide for $72-96$ hours produce massive diuresis even in the presence of renal failure and produce symptomatic relief of shortness of breath and even improvement of renal function. A patient is illustrated here to that effect. Continuous bumetanide infusion affords symptomatic relief and active rehabilitation not provided by any other therapy after end of infusion therapy.
\end{abstract}

\section{Introduction}

Renal failure is a consistent accompaniment of CHF. Renal failure progresses as $\mathrm{CHF}$ advances. Progressive renal failure is at least in part due to therapy for CHF such as use of angiotensin converting enzyme inhibitors (ACE1), angiotensin receptor blockers (ARB) or a combination of both without or with diuretics [1] Persistently low blood pressure produced by the above paradigm of therapy is a fundamental mechanism of decreased renal blood flow which determines sustained renal failure. In earlier stages of availability of ACE1/ARB, it was noted that this therapeutic approach is commonly accompanied by systemic hypotension and functional renal inefficiency, which may limit the utility of treatment in some patients [2,3].

Of these drugs adverse effects are the expected consequences of interference with renin-angiotensin system, which generally preserves systemic blood pressure and renal function in low output states [4]. As cardiac output and renal blood flow decline, renin is released from the kidney, the resulting increase in angiotensin II acts to support systemic perfusion and glomerular filtration pressure by systemic arteriolar and intrarenal efferent arteriolar vasoconstriction, respectively [5]. Consequently, when actions of angiotensin II are suppressed, systemic and intraglomerular pressures decline resulting in systemic hypotension and worsening renal function [6].

By step wise logistic regression analysis, only two variablesan elevated plasma renin activity and therapy with enalaprilindependently predicted a decrease in creatinine clearance in these patients with severe heart failure. When patients were separated into two groups on the basis of a pretreatment plasma renin activity of $5 \mathrm{ng} /$ $\mathrm{ml}$ per hour, only patients with a plasma renin activity of $\geq 5 \mathrm{ng} / \mathrm{ml} / \mathrm{h}$ showed a decrease in creatinine clearance after converting enzyme inhibition. In contrast, no notable changes in creatinine clearance was observed with lower renin values [6].
This finding asserts that active renin- angiotensin system (high renin) is essential to maintain normal blood pressure and renal hemodynamic state in states of low cardiac output such as severe chronic heart failure. Therefore, physiologically use of ACE1, ARB in chronic heart failure is unjustifiable from stand point of renal function. It is evident that suppression of renin-angiotensin system by ACE1/ ARB groups of drugs even without chronic heart failure can lead to rapid deterioration of renal function.

Here is an example to that effect.

A 65 year white male with biopsy proven focal glomerular sclerosis was followed by the author along with a military doctor from 19831991. When ACE1, Lisinopril was available in the market with great publicity of renoprotection, the military doctor placed him on Lisinopril. The result of rapid deterioration of renal function ending in hemodialysis therapy is shown in Table 1.

The above illustrates the most detrimental effect of ACE1 (Lisinopril) on renal function, electrolyte balance and hematopoietic system characterized by progressive renal failure, hyperkalemia and progressive anemia. The patient ended up treated with maintenance hemodialysis.

Correspondence to: Anil K. Mandal, 800 Zeagler Drive Suite 510, Palatka, Florida 32177, USA, Tel: (386) 530-4040, Fax: (386) 530-6795, E-mail: amandal@med-spec.com

Key words: pathophysiology of renal failure, fluid overload and electrolyte imbalance in severe congestive heart failure (CHF)

Received: September 03, 2016; Accepted: September 16, 2016; Published: September 21, 2016 
Table 1. Effect of lisinopril on renal function.

$63 y$ white male

\begin{tabular}{|c|c|c|c|}
\hline Year & $\begin{array}{l}\text { BUN/cr } \\
\mathrm{mg} / \mathrm{dl}\end{array}$ & $\begin{array}{c}\text { Serum K } \\
\text { mmol/l }\end{array}$ & $\begin{array}{c}\text { Hematocrit } \\
(\%)\end{array}$ \\
\hline 1983 & $29 / 1.9$ & N/A & 51 \\
\hline 1987 & $43 / 4.1$ & 4.6 & 41 \\
\hline 1989 & Lisinopril started & & \\
\hline$\# 1$ & $67 / 5.3$ & 5.8 & 35 \\
\hline$\# 2$ & $55 / 5.7$ & 5.6 & N/A \\
\hline$\# 3$ & $57 / 5.0$ & 6.1 & 34.6 \\
\hline 1990 & $54 / 5.7$ & $5.4^{*}$ & 36.2 \\
\hline 1991 & $71 / 9.3$ & $4.0^{*}$ & 34.4 \\
\hline
\end{tabular}

$\mathrm{Cr}=$ Serum creatinine

$\mathrm{N} / \mathrm{A}=$ Not Available

*After treatment with Sodium polystyrene sulfate (Kayexalate)

Therefore there is no justification of the use of ACE!/ARB in CHF which is associated with decreased renal function. What else can be done to relieve shortness of breath and treat fluid overload in patients with CHF.

Available alternative is to treat the fluid overload by use of single or a combination of diuretic. It is important to understand that efficacy of a diuretic to increasing urine output depends upon delivery of diuretic(s) into the renal tubules which will depend upon glomerular filtration rate (GFR). When GFR is decreased with use of ACE1/ARB group of drugs, delivery of diuretics in the tubules will be diminished resulting in impotent diuresis. Hence in order to improve diuresis, no drugs should be used which may inhibit GFR. Increasing the dose of diuretics doesn't necessarily increase diuresis.

\section{Paradigm of therapy in promoting diuresis and affording symptomatic relief in patients with severe CHF associated with advanced renal failure}

Loop diuretics consisting of furosemide (Lasix $\left.{ }^{\oplus}\right)$, torsemide $\left(\right.$ Demadex $\left.^{\star}\right)$, ethacrynic acid $\left(\right.$ Edecrin $\left.^{\star}\right)$, and bumetanide $\left(\right.$ Bumex $\left.^{\star}\right)$ are very potent diuretics. They can be administered orally, as intravenous boluses or by continuous intravenous infusion [7].

A. Oral diuretic therapy is efficacious in producing adequate diuresis and reducing swelling in those with normal or near normal function. Overtime diuretic effect decreases with progressive loss of potassium in the urine. As intracellular potassium is depleted, sodium takes the place of potassium inside the cells and hold water thereby resurging edema. The effect of diuretics in inducing diuresis can be maintained, if concomitantly spironolactone or amiloride is administered along with a loop diuretic. As renal function decreases in course of time with daily use of a diuretic, diuresis becomes impotent, thus requiring much higher doses of a diuretic to produce the same or even lesser response. This is called refractory state [8]

\section{B. Bolus injection of diuretic}

The following bolus injection of loop diuretics was recommended; Furosemide 100 to $200 \mathrm{mg}$, Bumetanide 8 to $10 \mathrm{mg}$, and torsemide 50 to $100 \mathrm{mg}$. The 2009 American College of Cardiology and American Heart Association guideline for patients with severe CHF recommended higher dose of furosemide or torsemide but lower dose of bumetanide as already stated [9].

Novelty of continuous intravenous infusion of bumetanide.
1). Rationale: The rationale for a continuous intravenous infusion of a diuretic as compared with bolus therapy is related to maintenance of an effective rate of drug excretion and therefore inhibition of sodium chloride reabsorption in the loop of Henle overtime. In contrast, bolus therapy is associated with initially higher and then lower rate, of diuretic excretion, as a result, sodium excretion may be at near maximal levels for the first two hours but thereafter decreases until the next dose is given.

2). A continuous intravenous infusion is safer in terms of ototoxicity than bolus injection of loop diuretics. Urine output is significantly higher with a continuous infusion than bolus therapy, although the difference is modest [11].

\section{3). Author's experience with continuous infusion of bumetanide.}

In the author's experience in a prospective fashion, continuous infusion of bumetanide is highly efficacious; however, the efficacy varies with the state of renal function at the initiation of infusion and fluid overload. Theoretically, in a state of end stage renal disease with serum creatinine $\geq 5 \mathrm{mg} / \mathrm{dl}$ or eGFR $\leq 10 \mathrm{ml} / \mathrm{min}$, massive diuresis with continuous diuretic infusion is inconceivable. Nonetheless, there are occasional patients with very low renal function such as chronic kidney disease CKD) stage 5 responds superbly to continuous infusion of bumetanide with good diuresis, symptomatic relief of shortness of breath, and even improvement of renal function.

A patient with severe CHF and CKD stage 5 is presented here to illustrate the successful outcome with continuous infusion of bumetanide.

RB, 81 yr. white female was admitted to a local hospital on May 24, 2016 for increased shortness of breath. She was very weak and frail. Her home medications consisted of flovent inhaler, bumetanide (Bumex ${ }^{\circledR}$ ) $4 \mathrm{mg}$ PO BID, gabapentin (Neurontin ${ }^{\star}$ ) $300 \mathrm{mg}$ at night PO, isosorbide mononitrate $30 \mathrm{mg}$ once daily, magnesium oxide $400 \mathrm{mg}$ twice daily, metoprolol $25 \mathrm{mg}$ twice daily and nitrobid sublingually as required. Laboratory studies done on May 24, 2016 showed hemoglobin 10.4 $\mathrm{g} / \mathrm{dl}$, hematocrit $34.2 \%$, brain natriuretic peptide (BNP) $1514 \mathrm{pg} / \mathrm{ml}$. laboratory studies done on May 25, 2016 revealed Bun/cr 50/3.28 $\mathrm{mg} / \mathrm{dl}$, eGFR $14 \mathrm{ml} / \mathrm{min}, \mathrm{Na}(+) / \mathrm{K}(+)$ 139/4.8. Because of Increased shortness of breath bumetanide (Bumex ${ }^{\otimes}$ ) infusion (drip)was started on May 28, 2016. Typically bumetanide infusion consists of $24 \mathrm{mg}$ bumetanide dissolved in $500 \mathrm{ml} 1 / 2$ normal or normal saline solution depending serum sodium level and titrated to deliver at $21 \mathrm{ml} /$ hour (approximately $1 \mathrm{mg} / \mathrm{h}$ )

Duration of infusion is usually for 72 to 96 hours depending on the extent of the diuresis. It has been observed that lower the kidney function, at the onset slower the initial response, and poorer the overall response.

Therapeutic response of diuretic infusion is assessed by

1). Intake and output chart

2). Symptomatic relief of shortness of breath

3). Decrease of swelling of the body

4). Electrolytes changes

5). BNP changes

Her intake, output and daily weight from May 28, 2016 to June 2, 2016 are presented in Table 2. 
Table 2. Daily intake, output, and weight.

\begin{tabular}{|c|c|c|c|c|c|c|}
\hline 2016 & May 28 & May 29 & May 30 & May 31 & June 01 & June 02 \\
\hline Total Intake (ml) & 370 & 571.1 & 512 & 1340 & 1150 & 240 \\
\hline Total Output (ml) & NA & 4950 & 2700 & 4000 & 4700 & 3500 \\
\hline Fluid (ml) Balance & +370 & -4378.9 & -2188 & -2660 & -3550 & -3260 \\
\hline I: Oral & 300 & 30 & 260 & 836 & & 240 \\
\hline I: IV & 70 & 541.1 & 252 & 504 & 1150 & \\
\hline O: Urine & & 4950 & 2700 & 4000 & 4700 & 3500 \\
\hline Weight (kg) & 77.000 & 73.600 & 71.000 & 69.400 & 67.700 & NA \\
\hline
\end{tabular}

$\mathrm{N} / \mathrm{A}=$ Not Available

$(+)=$ Positive balance

$(-)=$ Negative balance

Table 3. Hospital course and laboratory testing.

\begin{tabular}{|c|c|c|c|c|c|}
\hline \begin{tabular}{|l} 
Date \\
$(2016)$
\end{tabular} & $\begin{array}{c}\text { Symptoms } \\
\text { (shortness of breath) }\end{array}$ & Intake/Output & $\begin{array}{c}\text { BUN/Scr } \\
\text { (mg/dl) }\end{array}$ & $\begin{array}{c}\text { eGFR } \\
(\mathrm{ml} / \mathrm{min})\end{array}$ & $\begin{array}{l}\text { Serum K } \\
(\mathrm{mml} / \mathrm{L})\end{array}$ \\
\hline May 25 & N/A & N/A & $50 / 3.28$ & 14 & 4.8 \\
\hline May 28 & \multicolumn{5}{|c|}{ Bumex infusion initiated } \\
\hline $\begin{array}{l}\text { May } 28 \\
\text { Weight }(\mathrm{kg}) \text { : }\end{array}$ & $\begin{array}{l}3+ \\
77\end{array}$ & $370 / \mathrm{N} / \mathrm{A}$ & $33 / 1.97$ & 26 & 4.2 \\
\hline $\begin{array}{l}\text { May } 29 \\
\text { Weight }(\mathrm{kg}) \text { : }\end{array}$ & $\begin{array}{c}1+\text { to } 2+ \\
73.6\end{array}$ & $571.1 / 4950$ & $31 / 1.80$ & 29 & 4.0 \\
\hline $\begin{array}{l}\text { May } 30 \\
\text { Weight }(\mathrm{kg}) \text { : }\end{array}$ & $\begin{array}{l}\text { No shortness of breath } \\
71\end{array}$ & $572 / 2700$ & $28 / 1.62$ & 32 & 3.4 \\
\hline $\begin{array}{l}\text { May } 31 \\
\text { Weight }(\mathrm{kg}) \text { : }\end{array}$ & $\begin{array}{l}\text { No Shortness of breath/Alert } \\
\text { N/A }\end{array}$ & $1340 / 4000$ & $24 / 1.45$ & 37 & 3.0 \\
\hline $\begin{array}{l}\text { June } 1 \\
\text { Weight }(\mathrm{kg}) \text { : }\end{array}$ & $\begin{array}{c}\text { No shortness of breath/Alert } \\
67.7\end{array}$ & $1150 / 4700$ & $23 / 1.22$ & 45 & 3.6 \\
\hline June 2 & \multicolumn{5}{|c|}{ Bumex infusion discontinued } \\
\hline $\begin{array}{l}\text { June } 2 \\
\text { Weight }(\mathrm{kg}) \text { : }\end{array}$ & No shortness of breath/Alert & $240 / 3500$ & $23 / 1.25$ & 44 & 3.5 \\
\hline Aug 10 (Office) & No shortness of breath & N/A & $38 / 1.65$ & 32 & 3.4 \\
\hline
\end{tabular}

$\mathrm{N} / \mathrm{A}=$ Not available

$\mathrm{Scr}=$ Serum creatinine

eGFR $=$ Estimated glomerular filtration rate

\section{Outcome of continuous bumetanide infusion in the patient illustrated}

Continuous bumetanide infusion promptly increased her urine output. Hourly urine output was $206.25 \mathrm{~mL}$ on May 29, $112.5 \mathrm{~mL}$ on May 30, $166 \mathrm{~mL}$ on May 31, $195.8 \mathrm{~mL}$ on June 1, and $145.8 \mathrm{~mL}$ on June 2. Her hospital course and serial laboratory testing are presented in Table 3.

It should be noted that her urine output was not as high as expected, mainly due to low renal function (eGPR $14 \mathrm{~mL} / \mathrm{min}$ ) at the onset of infusion. However, no information is available in the literature what will be the maximum urine output by continuous infusion of $1 \mathrm{mg}$ bumetanide per hour. One thing is certain, that lower the kidney function at the initiation of infusion, lower will be the total urine volume. Although her kidney function in terms of the eGFR improved from CKD stage 5 to CKD stage 2, during the infusion, the urine output didn't proportionately increase. Thus the cause and effect relationship between bumetanide infusion and improvement in renal function and extent of diuresis is poorly understood. Increase in eGFR may be caused by increased urine flow or improvement in heart function and increased cardiac output. Improvement in heart function is manifested by decrease in BNP as shown in Table 4.

After discharge from the hospital she was sent to a nursing home for rehabilitation then went home. She is weak but lives alone and makes her food and came to author's office driving her own car. She
Table 4. Results of BNP.

\begin{tabular}{|c|c|}
\hline Date (2016) & BNP assay $\mathbf{( p g / m L )}$ \\
\hline May 24 & 1514 \\
\hline May 29 & Bumex infusion running \\
& 1334 \\
\hline June 2 & Bumex infusion discontinued \\
& 352 \\
\hline
\end{tabular}

is not short of breath. Her kidney function is slightly decreased, CKD stage 3 due to continuous use of diuretic.

\section{Critical comments on the salutary effects of continuous intravenous infusion of bumetanide in CHF associated with severe renal failure}

1. Vigilant care is essential to monitor fluid balance (output/ intake), electrolytes and renal function changes during the infusion period and at least for several weeks after the infusion is discontinued. If the urine volume is high during the infusion, effective circulating volume will decrease rapidly, leading to a decrease in kidney function which will rapidly decrease diuretic response. In order to avoid this scenario, it is important to replace at least $10 \%$ of the urine volume by replacement fluid. Since sodium is lost hugely with diuretic infusion and hyponatremia is a common feature during the diuretic infusion, isotonic saline $(0.9 \%)$ solution is the ideal solution to be infused at a rate of 50 to $75 \mathrm{~mL}$ per hour, delivering 1200 to $1800 \mathrm{~mL}$ per 24 hours depending on the urine flow rate and renal function changes. In the 
patient illustrated here, replacement fluid was not required because her renal function steadily improved and urine output was not high.

2. Electrolytes And Acid Base changes: they are common and consist of loss of cations sodium, potassium and magnesium, and $\mathrm{H}+$ ions. These cations and anions are lost in the urine, resulting in hyponatremia, hypokalemia, hypomagnesemia, and metabolic alkalosis. Depleted intravascular volume and $\mathrm{K}$ ion promote bicarbonate reabsorption in the proximal tubules and more so in the distal tubules. Thus, physiologically, hypokalemia and metabolic alkalosis go hand and hand. Clinically, hypokalemia and metabolic alkalosis are very significant and may give rise to cardiac arrhythmia and high mortality. Both hypokalemia and metabolic alkalosis can be treated by adding $40 \mathrm{meq} \mathrm{Kcl}$ in the isotonic saline infusion bag. Chloride will be absorbed and bicarbonate will be excreted in urine. Metabolic alkalosis will be monitored by daily arterial blood gas analysis which will provide the $\mathrm{pH}$ and bicarbonate level. If $\mathrm{pH}$ goes above 7.50 , acetazolamide $\left(\right.$ Diamox $\left.^{\otimes}\right) 500 \mathrm{mg}$ IV every 8 to 12 hours should be prescribed to enhance bicarbonate excretion and reduce alkalemia. In order to control hypokalemia at a faster rate, $\mathrm{K}$ sparing diuretics such as spironolactone $50 \mathrm{mg}$ PO Q 8 hour or 6 hour or amiloride 5 to $10 \mathrm{mg}$ daily may be prescribed. These $\mathrm{K}$ sparing diuretics enhance diuresis to an extent. Magnesium depletion: Hypomagnesium is often treated by PO replacement by magnesium oxide $400 \mathrm{mg}$ TID, however, magnesium is laxative therefore absorption is erratic. In severe magnesium depletion such as magnesium level of less than $1.5 \mathrm{mg} / \mathrm{dl}$, magnesium replacement should be given as magnesium sulfate $50 \%$ solution $2 \mathrm{~g} 1 \mathrm{M}$ every 6 hour for 4 doses which will correct hypomagnesemia in a sustained fashion.

Severity and mortality of CHF. Risk assessment of 3- year cumulative fatal and non-fatal cardiovascular events as well as frequency of rehospitalization was determined in 388 patients with CHF during a period of 3 years. These patients were treated with ACE1, ARB, beta blockers, mineralocorticoid receptor antagonists and antiplatelet drugs. No mention was made that they were treated with bolus diuretic or continuous infusion of a diuretic. During follow up, 110 cardiovascular events (including 43 fatal cases) were determined, thirty five patients died due to advanced CHF (32\%). Additionally 74 subjects were readmitted into hospital after discharge from the hospital due to worsening CHF. Thus the mortality rate of $32 \%$ and rehospitalization rate of $74 \%$ are very high [12]. In author's experience ACE1 and ARB drugs have something to do with that. Author's patient with CHF illustrated here didn't receive renin-angiotensin inhibitor drugs.

Maintenance therapy following diuretic infusion. The author typically prescribes PO bumetanide (Bumex $\left.{ }^{\circledR}\right) 2 \mathrm{mg}$ PO twice daily. Bumetanide should be started at least 48 hours before discontinuation of infusion. There are no clinical studies available with regard to maintenance therapy.

\section{Pearl of wisdom}

1). Continuous infusion of bumetanide is an effective and safe therapy to treat severe CHF without or with variable degree of renal failure.

2). Continuous infusion of bumetanide produces variable diuresis, depending on renal function at the time of onset of infusion, symptomatic relief of shortness of breath which last for quite some time. Maintenance of relief can be prompted by prescribing PO bumetanide

3). Renal function recovery is common which helps to maintain the effect of infusion

4). Electrolytes imbalance can be averted by close monitoring of the patients and obtaining laboratory daily.

5). Continuous infusion of bumetanide is a good substitute for dialysis therapy in severe CHF associated with advanced renal failure.

6). In addition, authors study on continuous bumetanide infusion in $\mathrm{CHF}$ is expected to reduce mortality and rehospitalization rate in severe CHF.

\section{References}

1. Mandal A K, Market RJ, Saklayen M, Mankus RA, Yokokawa K (1994) Diuretics potentiate angiotensin converting enzyme inhibitor-induced acute renal failure. Clin Nephrol 42: 170-174.

2. Packer M (1985) Converting-enzyme inhibition for severe chronic heart failure: views from a skeptic. Int J Cardiol 7: 111-120. [Crossref]

3. Packer M, Kessler PD, Gottlieb SS (1986) Adverse effects of converting enzyme inhibition in patients with severe congestive heart management. Post graduate Med $J$ S-179-82.

4. Packer M (1985) Is the renin- angiotensin system really unnecessary in patients with severe chronic heart failure? The price we pay for interfering with evolution (editorial). J AM Coll Cardiol 6: 171-3.

5. Ichikawa I, Pfeffer JM, Pfeffer MA, Hostetter TH, Brenner BM (1984) Role of angiotensin II in the altered renal function of congestive heart failure. Circ Res 55: 669-675. [Crossref]

6. Parker M, Hunglee W, Kessler PD, et al SS (1987) Identification of hyponatremia as a risk factor for the development of renal insufficiency during converting enzyme inhibition in severe chronic heart failure. JACC 10: 837-844.

7. Mandal AK (2014) Effectiveness of bumetanide infusion in treatment of generalized edema and congestive heart failure. Open Journal of Internal Medicine 4 : 73-81.

8. Voelker JR, Cartwright-Brown D, Anderson S, Leinfelder J, Sica DA, et al. (1987) Comparison of loop diuretics in patients with chronic renal insufficiency. Kidney Int 32: 572-578. [Crossref]

9. Hunt SA, Abraham WT, Chin M H (2009) focused update incorporated into the ACC AHA 2005 guidelines for the diagnosis and management of heart failure in adults. A report of the American College of Cardiology Foundation Task Force on practice guidelines. Circ 119: e391-e479.

10. Dargie HJ, Allison ME, Kennedy AC, Gray MJ (1972) High dosage metolazone in chronic renal failure. $\mathrm{Br}$ Med J 4: 196-198. [Crossref]

11. Salvador DRK, Punzalan FE, Ramos GC (2005) Continuous infusion versus bolus injection of loop diuretics in congestive heart failure.The Cochrane Library.

12. (2015) BBA clinical 3: 16-24.

Copyright: (C2016 Mandal AK. This is an open-access article distributed under the terms of the Creative Commons Attribution License, which permits unrestricted use, distribution, and reproduction in any medium, provided the original author and source are credited. 